J. Nepal Chem. Soc., vol. 29, 2012

\title{
One pot Aziridation of 2,3-trans Stilbene with Chloramine T derivatives in the presence of catalyst phenyltrimethyl Ammonium Tribromide
}

\author{
Susan Joshi \\ Central Department of Chemistry, Tribhuvan University, Kirtipur, Kathamandu, Nepal \\ Email: susanjoshi68@gmail.com
}

\begin{abstract}
Phenyltrimethyl ammonium tribromide is an excellent source of bromine which was found to be an efficient catalyst for aziridination of 2,3-trans stilbene utilizing Chloramine $T$ derivatives as a practical nitrogen source. Chloramine $T$ derivatives were examined and were found to give the corresponding trans-2,3-diphenyl-N-arylsulfonyl aziridines in good yields.
\end{abstract}

Keywords: trans-2,3-diphenyl-N-arylsulfonyl aziridines, 2,3-trans stilbene, Chloramine T, Phenyltrimethyl ammonium tribromide

\section{Introduction}

Aziridines are useful as building blocks for the synthesis of nitrogen containing functional compounds due to their highly regio and stereoselective ring opening reaction ${ }^{\text {P. }}$. They are found in some natural products as well as biological active compounds such as mitomycin and azinomycines ${ }^{4,5}$. Novel anti-tumour agents related to mitomycin have recently been synthesized and shown to posses activity against a variety of Cancers ${ }^{6,7}$. Thus aziridines are worthy targets for the synthetic organic chemist and it is essential that efficient methods exist for the facile synthesis of a range of structurally diverse aziridines. Among the various classes of aziridines the $\mathrm{N}$-arylsulfonyl derivatives are more on counts because of the presence of the highly electron withdrawing arylsulfonyl group on nitrogen should make these aziridines highly electrophilic and so more susceptible to attack by nucleophiles ${ }^{8}$.

Various synthetic methods have been developed to prepare transition metal catalyzed aziridination based on ( $\mathrm{N}$ - p-toluenesulfonylimine) phenyliodinane as the nitrenoid source ${ }^{9,10}$. Despite these advances, catalytic aziridination has not yet entered the realm of practical organic synthesis, mainly due to the expense and inconvenience of (N-p-toluene sulfonylimine) phenyliodinane as a reagent.

Sharpless and his coworker have been reported the most impressive methodology utilizing chloramines $\mathrm{T}$ as a nitrogen source to aziridation of the olefins in the presence of transition metal catalyst ${ }^{12-14}$. Komatsu and his coworker have been reported the interesting Chloramine T/iodine catalyzed aziridation of alkenenes ${ }^{15}$.

Although a variety of routes leading to aziridines have been developed to date, but no example of aziridation utilizing chloramines $\mathrm{T}$ with trans stilbene in the presence of catalyst have appeared. This new one pot synthetic transformation involves phenyltrimethylammonium tribromide (PTAB) catalyzed aziridation of the trans stilbene utilizing Chloramines T.

\section{Experimental Methods}

Melting points and boiling points are uncorrected. IR spectra ( $\mathrm{KBr}$ pellets or liquid film) were recorded on Nicolet 5DX FTIR Instrument and NICOLET PROTÉGÉ 460 FTIR Instrument. ${ }^{1} \mathrm{H}$ NMR 
$\left(\mathrm{CDCl}_{3}\right.$, internal standard TMS) were recorded on a JOEL FX-100 machine at $100 \mathrm{MHz}$ and DPX-300 Brucker Machine at $300 \mathrm{MHz}$. Microanalyses were carried out on a Perkin Elmer $240 \mathrm{CHN}$ Elemental Analyser.

Progress of reactions was monitored by TLC (silica gel impregnated with $13 \%$ plaster of paris). Unless otherwise specified, anhydrous sodium sulphate was used as drying agent. All reagents and solvents were purified and dried when required using standard methods.

\section{General method for the preparation of trans-2,3-diphenyl-N-arylsulphonylaziridine}

A mixture of trans- stilbene (3 mmole) and the appropriate chloramine $(3.3 \mathrm{mmole})$ in $15 \mathrm{ml}$ of acetonitrile was added to phenyltrimethylammonium tribromide $(0.3 \mathrm{mmole})$ at room temperature and the resulting mixture stirred for 12 hours. The progress of the reaction was monitored by TLC. After completion of the reaction, the reaction mixture was concentrated and filtered through a short column of silica gel (3 x $4 \mathrm{~cm}, 10 \%$ ethyl acetate in hexane). Evaporation of the solvent, gave a solid which was purified by crystallisation from benzene-petroleum ether to afford the corresponding trans-2,3-diphenyl$\mathrm{N}$-arylsulphonylaziridine.

\section{Chloramine B}

It was prepared according to the literature procedure ${ }^{16}$. The Chloramine $\mathrm{B}$ was dried at $80^{\mathrm{O}} \mathrm{C}$ for 12 hours in drying pistol.

\section{Trans-2,3-diphenyl-N-benzenesulphonylaziridine}

Trans-stilbene $(0.54 \mathrm{~g}, 3 \mathrm{mmole})$ was reacted with chloramine $\mathrm{B}(0.627 \mathrm{~g}, 3.3 \mathrm{mmole})$ in the presence of phenyltrimethylammonium tribromide $(0.1128 \mathrm{~g}, 0.3$ mmole $)$ according to the general procedure and the resulting mixture stirred for 12 hours at room temperature. Work-up gave a solid which was purified by crystallisation from benzene-petroleum ether to get $0.985 \mathrm{~g}$, $(89 \%)$ of the title compound, mp $124-26^{\circ}\left(\right.$ Lit. $\left.^{164} \mathrm{mp} 125-26^{\circ}\right)$

IR(KBr): 1350 and $1150 \mathrm{~cm}^{-1}$, no NH stretching

${ }^{1} \mathrm{HNMR}$ : $\delta 7.5$ (doublet, $2 \mathrm{H}$ aromatic protons, $\mathrm{J}=8 \mathrm{~Hz}$ ), 7.25 (multiplate, $13 \mathrm{H}$ aromatic protons,) 4.21 (singlet,2H)

Elemental analysis: Observed C 71.34, H 5.35, Calculated C 71.64, H 5.07

\section{Chloramine $T$}

It was prepared according to the literature procedure ${ }^{\mathbf{1 6}}$. The Chloramine $\mathrm{T}$ was dried at $80^{\mathrm{O}} \mathrm{C}$ for 12 hours in drying pistol

\section{Trans-2,3-diphenyl-N-p-toluenesulphonylaziridine}

Trans-stilbene ( $0.54 \mathrm{~g}, 3$ mmole) was reacted with chloramine $\mathrm{T}(0.673 \mathrm{~g}, 3.3 \mathrm{mmole})$ in the presence of phenyltrimethylammonium tribromide $(0.1128 \mathrm{~g}, 0.3 \mathrm{mmole})$ according to the general procedure and the resulting mixture stirred for 12 hours at room temperature. Work-up gave a solid which was purified by crystallisation from benzene-petroleum ether to get $0.947 \mathrm{~g},(82 \%)$ of the title compound, mp 138$9^{\circ}\left(\right.$ Lit. $\left.^{164} \mathrm{mp} 138-9^{\circ}\right)$.

IR(KBr): 1350 and $1150 \mathrm{~cm}^{-1}$, no NH stretching

${ }^{1} \mathrm{HNMR}$ : $\delta 7.55$ ( doublet, $2 \mathrm{H}$ aromatic protons, $\mathrm{J}=8 \mathrm{~Hz}$ ), 7.25 (multiplate, $12 \mathrm{H}$ aromatic protons,) 4.22 (singlet, 2H), 2.4(singlet, 3H)

Elemental analysis: Observed C 72.38, H 5.6 Calculated C 72.20, H 5.44 


\section{Chloramine C}

It was prepared according to the literature procedure ${ }^{16}$. The Chloramine $\mathrm{C}$ was dried at $80^{\circ} \mathrm{C}$ for 12 hours in drying pistol.

\section{Trans-2,3-diphenyl-N-chlorobenzenesulphonylaziridine}

Trans stilbene $(0.54 \mathrm{~g}, 3$ mmole) was reacted with Chloramine $\mathrm{C}(0.739 \mathrm{~g}, 3.3 \mathrm{mmole})$ in the presence of phenyltrimethylammonium tribromide $(0.1128 \mathrm{~g}, 0.3 \mathrm{mmole})$ according to the general procedure and the resulting mixture stirred for 12 hours at room temperature. Work-up gave a solid which was purified by crystallization from benzene-petroleum ether to get $0.989 \mathrm{~g},(81.24 \%)$ of the title compound, mp $117-8^{\circ}\left(\right.$ Lit. $\left.^{164} \mathrm{mp} 117-8^{\circ}\right)$.

IR(KBr): 1350 and $1150 \mathrm{~cm}^{-1}$, no NH stretching

${ }^{1}$ HNMR: $\delta 7.9$ ( doublet, $2 \mathrm{H}$ aromatic protons, $\mathrm{J}=8 \mathrm{~Hz}$ ), 7.25 (multiplate, $12 \mathrm{H}$ aromatic protons,) 4.21 (singlet, $2 \mathrm{H}$ )

Elemental analysis: Observed C 64.80, H 4.28, Calculated C 64.95, H 4.33

\section{Result and Discussion}

phenyltrimethylammonium tribromide is known as PTAB. This catalyst is good source of bromine for the synthesis of trans-2,3-diphenyl $\mathrm{N}$-arylsulfonylaziridine from trans stilbene and Chloramines $\mathrm{T}$.

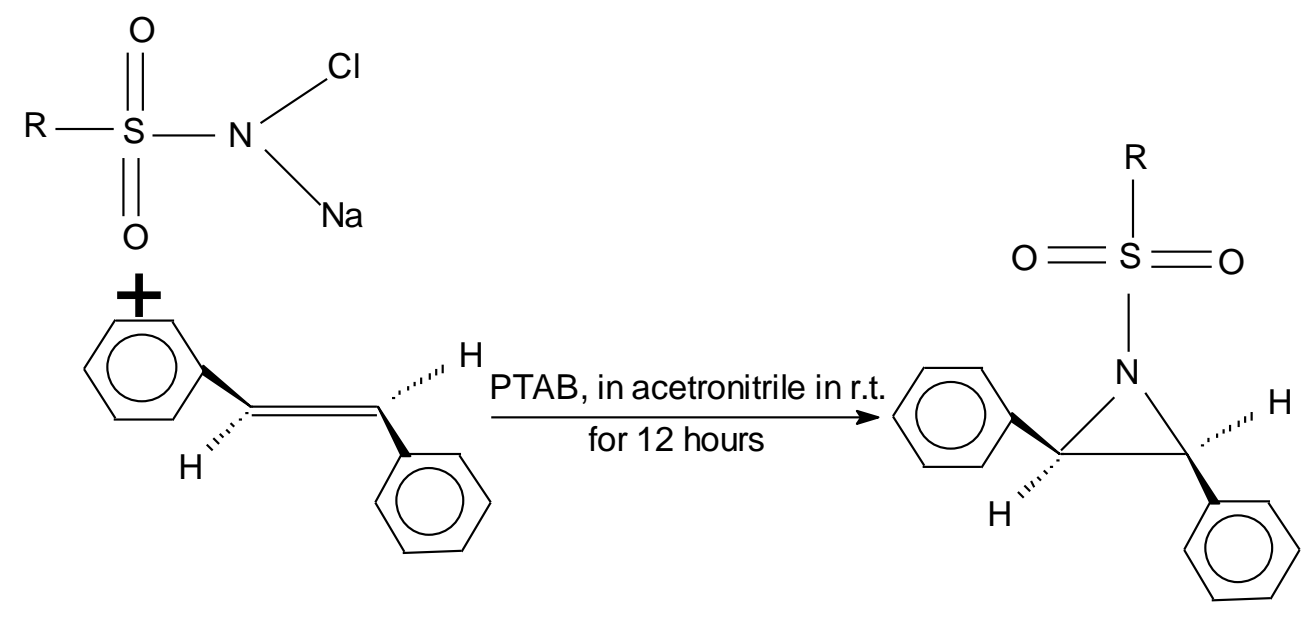

$\mathrm{R}=\mathrm{Ph}$

$\mathrm{R}=\mathrm{p}-\mathrm{CH} 3 \mathrm{C} 6 \mathrm{H} 4$

$\mathrm{R}=\mathrm{p}-\mathrm{Cl}-\mathrm{C} 6 \mathrm{H} 4$

In this transformation phenyltrimethylammonium tribromide functions as the source of the positive bromine species $(\mathrm{Br}-\mathrm{X})$ which initiates the catalytic cycle and probably also a solid liquid phase transfer catalyst aiding the dissolution of Chloramines $\mathrm{T}$ in acetronitrile and trans stilbene provided the corresponding aziridine stereospecifically in good yield. 


\section{Scheme I}

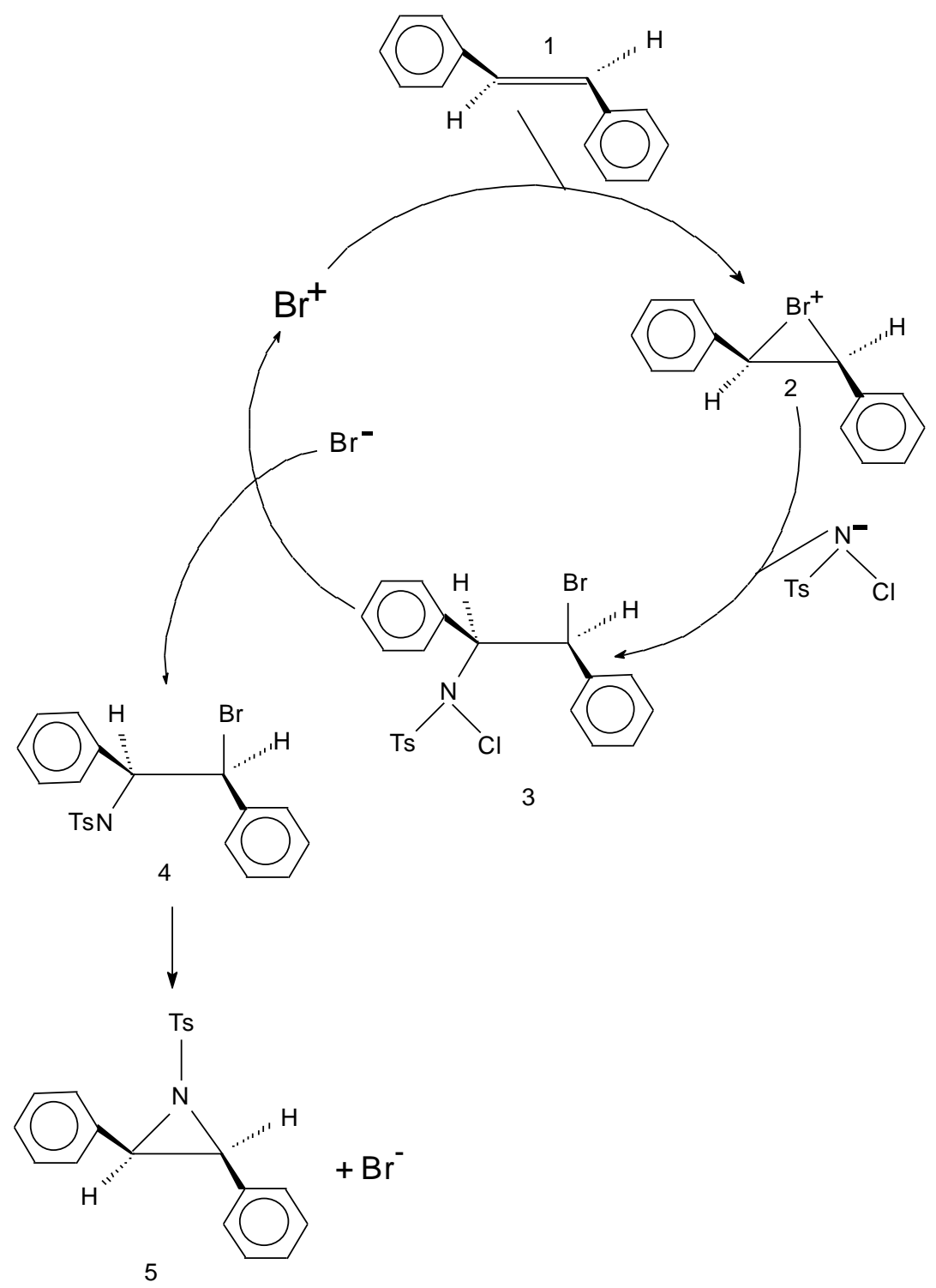

$\mathrm{Br}-\mathrm{X}, \mathrm{X}=\mathrm{Cl}$, TsNCl, Br etc

Proposed Mechanism of the aziridination of trans-stilbene

The proposed pathway for this bromine catalyzed aziridination process is shown in Scheme I taking trans stilbene as the specific case.

Initially, the trans stilbene reacts with a $\mathrm{Br}+$ source $(\mathrm{Br}-\mathrm{X})$ to give the bromonium ion 2 which then suffers benzylic opening by $\mathrm{TsNCl}^{-}$forming $\beta$ - $\mathrm{N}$-chloro- $\mathrm{N}$-toluenesulfonamide 3 . Attack of $\mathrm{Br}$ anion (or $\mathrm{TsNCl}^{-}$) on the $\mathrm{N}-\mathrm{Cl}$ group in putative intermediate 3 generates the anion 4 and a(Br-X) species. Expulsion of $\mathrm{Br}$ anion from the anion 4 finally yields the trans-2, 3-diphenyl- $\mathrm{N}$-arylsulfonyl aziridines 5 and the regenerated $\mathrm{Br}-\mathrm{X}$ species is ready to initiate another turn of the catalytic cycle. 
J. Nepal Chem. Soc., vol. 29, 2012

\section{Conclusion}

I have found a simple one pot aziridation of trans stilbene with Chloramine $\mathrm{T}$ derivatives in the presence of phenyltrimethylammonium tribromide (PTAB) catalyst. From this process trans-2,3diphenyl-N-arylsulfonyl aziridines are transformed in good yields. Use of Chloramine $\mathrm{T}$ derivatives are very attractive because it is inexpensive and its trans-2,3-diphenyl- $\mathrm{N}$-arylsulfonyl aziridines derivatives tend to be crystalline.

\section{Acknowledgement}

The author wish to acknowledge support of this research by Asian Development Bank and author also acknowledge to late Prof. Nadir U. K. (Indian Institute of Technology, Delhi).

\section{References}

1. D. Tanner, Angew. Chem., Int. Ed. Engl, 1994, 33, 599.

2. P. E. Maligres, M. M. See, D. Askin, P. J. Reider, Tetrahedron Lett .1997, 5253.

3. T. Ibuka, Chem. Soc. Rev. 1998, 27, 145.

4. J. A. Deyrup, In Chemistry of Heterocyclic Compound, A. Hassners, E. Wiley: New York, 1983, 42, 1214.

5. M. Kasai, M. Kono, Synlett, 1992, 778790.

6. I. Han, H. Kohn, J. Org. Chem, 1991, 56, 4648.

7. E. B. Skibo, I. Islam, M. J. Heileman, W. G. Schulz, J. Med. Chem,1994,37,78.

8. A. P. Kozikowski, H. Ishida and K. Isobe, J. Org. chem., 1979, 44, 2788

9. D. A. Evans, M. M. Faul, M. T. Bilodeau, J. Org. Chem., 1991, 56, 6744

10. R. E. lowenthal, S. Masumuno, Tetrahedron Lett., 1991, 7373

11. Z. Li., Conser, Ta, N. Jacoben, J.A. Chem. Soc., 1993, 115, 5326

12. G. Li., H. T.. Chang, K. B. Sharpless, Angew, Chem. Int. Ed. Engl. 1996, 35, 451-454

13. K. B. Sharpless, A. O. Chong; K. Oshima, J.Org. Chem. 1976, 41, 177-179

14. A. E. Rubin, K. B. Sharpless, Angew, Chem. Int. Ed. Engl., 1997, 36, 2637-2640

15. A. Takeya, K. Daisuke, S. Minakata, R. Ilhyong, M. Komatsu, Tetrahedron 1998, 54, 1348513494.

16. B. S. Furniss, A. J. Hannaford, P.W. G. Smith, A. R. Tatchell, Vogel's Textbook of Practical Organic Chemistry, $5^{\text {th }}$ edition, ELBS Longman 1989, pp883 